\title{
Ensino de Nomeação com Objetos e Figuras para Crianças com Autismo
}

\author{
Edson Luiz Nascimento dos Santos ${ }^{1}$ \\ Carlos Barbosa Alves de Souza \\ Universidade Federal do Pará
}

\begin{abstract}
RESUMO - Este estudo comparou a utilização de estímulos bidimensionais e tridimensionais em um procedimento de instrução com múltiplos exemplares para instalar nomeação (integração dos repertórios de falante e ouvinte) em quatro crianças com autismo. Após uma linha de base de nomeação (Fase 1), treinou-se discriminação condicional por identidade com o experimentador tateando os estímulos modelo, discriminação condicional auditivo-visual e tato com novos estímulos (Fase 2). Atingido o critério na Fase 2, a Fase 1 foi replicada (Fase 3). Observada nomeação na Fase 3, a Fase 1 foi replicada com novos estímulos (Fase 4). Dois participantes demonstraram nomeação. Discute-se a efetividade do procedimento de instrução com múltiplos exemplares, o papel da modalidade de estímulos e a interação entre os repertórios de falante e ouvinte.
\end{abstract}

Palavras-chave: nomeação, instrução com múltiplos exemplares, estímulos bi e tridimensionais, autismo

\section{Teaching Naming with Objects and Figures for Children with Autism}

\begin{abstract}
The current study compared the use of two- and three-dimensional stimuli in a multiple exemplar instruction procedure to install naming (integration of speaker and listener repertoires) in four autistic children. Phase 1 evaluated the baseline of naming. Phase 2 trained identity conditional discrimination with the experimenter tacting the sample stimuli, auditory-visual conditional discrimination and tact with new stimuli. After reaching criterion in Phase 2, Phase 1 was replicated to verify the emergence of naming (Phase 3). Having observed naming in Phase 3, Phase 1 was replicated with new stimuli (Phase 4). Two participants showed acquisition of naming. The effectiveness of the multiple exemplar instruction procedure, the role of stimuli modality and the interaction between speaker and listener repertoires are discussed.
\end{abstract}

Keywords: naming, multiple exemplar instruction, two- and three-dimensional stimuli, autism

A integração entre os repertórios de falante e ouvinte tem sido apontada como um aspecto fundamental para o desenvolvimento de comportamentos simbólicos ou emergentes (Greer \& Longano, 2010; Greer \& Ross, 2008; Greer \& Speckman, 2009; Horne \& Lowe, 1996). Essa integração é central na caracterização do repertório comportamental definido como nomeação por Horne e Lowe (1996).

Horne e Lowe (1996) caracterizam nomeação como uma relação comportamental bidirecional que integra funções de falante e ouvinte tal que a presença de uma pressupõe a outra. Quando, ao observar uma pessoa nomear um determinado estímulo, uma criança aprende, sem treino direto, respostas de falante e ouvinte àquele estímulo, diz-se que essa criança adquiriu o repertório chamado nomeação. Por exemplo, ao ouvir uma pessoa dizendo lápis diante do estímulo lápis, a criança pode ser capaz de pegar o lápis quando solicitada (comportamento de ouvinte) e dizer lápis quando uma pessoa perguntar o que é isso? (comportamento de falante).

Alguns estudos afirmam que os repertórios de falante e ouvinte são inicialmente independentes, ou seja, o aprendizado de um não implica a emergência do outro (Greer \& Longano, 2010; Greer \& Speckman, 2009; Horne \& Lowe, 1996; Skinner, 1957/1992). Segundo Horne e Lowe (1996),

1 Endereço para contato: Universidade Federal do Pará, Núcleo de Teoria e Pesquisa do Comportamento. Campus Básico, Avenida Augusto Correa 1, Belém, PA, Brasil. CEP: 66075-110. E-mail: edsonsantos_87@hotmail.com a nomeação se estabelece durante a história de aquisição independente dos repertórios de ouvinte, ecóico e tato ${ }^{1}$.

$\mathrm{Na}$ aquisição do repertório ecóico, uma pessoa pode, ao apontar para um estímulo como um carro, dizer carro ou diga carro. A resposta esperada seria uma resposta vocal foneticamente correspondente, ou ao menos aproximada, da resposta da pessoa. Caso a criança já apresente comportamento de ouvinte para o estímulo carro, o ensino de ecóico pode ocasionar também respostas de ouvinte (o ecóico da criança gera uma estimulação auditiva funcionalmente equivalente ao comportamento verbal que ela escutou, podendo funcionar como estímulo antecedente para respostas de ouvinte e novos ecóicos). Nesse momento, a criança começa a integrar os repertórios, tornando-se falante e ouvinte com respeito a seu próprio estímulo verbal.

O elo final da relação da nomeação implica a aquisição do tato. Esse repertório se estabelece nas mesmas situações mencionadas antes nas quais uma pessoa aponta para um estímulo e diz o seu nome. Essa estimulação verbal ocasiona comportamentos de ouvinte da criança e ecóicos. Com treinos repetidos, o estímulo torna-se discriminativo e vê-lo é suficiente para ocasionar a resposta verbal da criança. Desse momento em diante, o próprio estímulo ocasiona respostas

1 Ecóico: operante verbal controlado por estímulos antecedentes verbais e mantido por reforçamento generalizado, em que há correspondência ponto-a-ponto e similaridade formal entre antecedente e resposta. Tato: operante verbal controlado por estímulos antecedentes não verbais e mantido por reforçamento generalizado (Skinner, 1957/1992). 
de tato e de ouvinte da criança, sem estimulação verbal de uma pessoa. $\mathrm{O}$ próprio tato emitido pela criança ocasiona novamente comportamentos de ouvinte ao objeto (e.g., vê-lo ou orientar-se a ele; Horne \& Lowe, 1996).

Horne e Lowe (1996) afirmam que uma vez que o indivíduo tenha passado por diversas experiências de aprendizado da relação de nomeação, esta se torna um operante de ordem superior, não exigindo reforçamento direto para que ocorra em novas situações. Assim, é suficiente que a criança aprenda uma resposta de ouvinte para um estímulo (e.g., pegar $\mathrm{x}$ diante do pedido Pegue $x$ ) ou aprenda a tatear esse estímulo, para que a relação completa de nomeação seja evocada.

$\mathrm{Na}$ última década, Horne, Lowe e colaboradores conduziram uma série de estudos experimentais com a finalidade de verificar empiricamente o papel da aquisição dos componentes da nomeação na aprendizagem de relações de estímulos arbitrárias. Os achados indicam que o treino de tatos vocais é suficiente para a aquisição de comportamentos de ouvinte e formação de classes arbitrárias de estímulos (Horne, Hughes, \& Lowe, 2006; Horne, Lowe, \& Randle, 2004; Lowe, Horne, Harris, \& Randle, 2002; Lowe, Horne, $\&$ Hughes, 2005); que o treino apenas de comportamentos de ouvinte não é suficiente para a formação de classes arbitrárias de estímulos (Horne et al., 2004); que o treino de tato pode produzir repertório de ouvinte aos estímulos e formação de classes arbitrárias independentemente da topografia ensinada (tato vocal ou gestual) e transferência de função para algumas crianças (Horne et al., 2006; Horne, Lowe, \& Harris, 2007; Lowe et al., 2005); e que o ensino de repertório de ouvinte comum para alguns estímulos pode estabelecer o repertório de tateá-los e categorização apenas para os participantes que tatearam os estímulos (Horne et al., 2006).

Influenciados pela proposta de Horne e Lowe (1996), Greer e colaboradores (e.g. Greer \& Longano, 2010; Greer \& Ross, 2008; Greer \& Speckman, 2009) definem nomeação como a fusão dos repertórios de falante e ouvinte, caracterizando um estágio do desenvolvimento verbal no qual um indivíduo pode aprender incidentalmente (i.e., sem contato direto com reforçamentos, correções ou pareamentos sistemáticos de estímulos) repertórios de falante e ouvinte em uma relação bidirecional. Além disso, diferentemente de Horne e Lowe (1996), Greer e colaboradores investigam o efeito de diferentes variáveis no estabelecimento do repertório de nomeação, com ênfase no papel do procedimento de instrução com múltiplos exemplares (ICME) no ensino de nomeação em pessoas com atraso no desenvolvimento e/ou linguagem.

Greer e Ross (2008) afirmam que a ICME envolve a formação de controle conjunto de estímulos e integração de repertórios inicialmente independentes. Por meio da variação de diferentes respostas a um estímulo, indivíduos adquirem a capacidade de aprender incidentalmente múltiplas respostas a partir do ensino de apenas uma. Segundo Greer e Longano (2010), para o uso da ICME no ensino de nomeação, primeiro, deve-se testar a presença ou não do repertório de nomeação com estímulos desconhecidos ou não familiares para o indivíduo. Um conjunto de estímulos visuais deve ser apresentado para o indivíduo em arranjos de pareamento ao modelo por identidade, mas com o experimentador dizendo o nome do estímulo modelo (treino do repertório de discriminação condicional por identidade - DCI+tato), simulando, de acordo com os autores, as situações naturais de aquisição de nomeação. Após atingir o critério de precisão no treino DCI+tato, são realizados testes dos repertórios de ouvinte (apontar para o estímulo em uma tentativa de discriminação condicional auditivo visual [DCAV]) e de falante (tatear o estímulo diante da pergunta $O$ que é isso?). Aqueles indivíduos que não apresentam os repertórios testados, ou apresentam apenas o de ouvinte, são expostos ao procedimento de ICME com outro conjunto de estímulos desconhecidos: os repertórios de DCI+tato, DCAV e tato são ensinados em tentativas intercaladas com diferentes estímulos (i.e., o mesmo estímulo não é apresentado sucessivamente em tentativas dos repertórios de ouvinte e de falante) até ser atingido um critério de precisão em cada repertório para cada estímulo. Em seguida, são repetidos os testes dos repertórios não aprendidos com o primeiro conjunto. O sucesso nesses testes sugere a presença do repertório de nomeação (o procedimento usado com o primeiro conjunto pode ser repetido com um novo conjunto de estímulos para garantir a robustez dessa conclusão).

Greer, Stolfi, Chavez-Brown e Rivera-Valdes (2005) verificaram se crianças de 2 anos e 5 meses a 4 anos, com atraso no desenvolvimento e/ou linguagem que falhavam nos testes de nomeação poderiam ter sucesso após a ICME. Os resultados mostraram a integração dos repertórios de falante e ouvinte com o conjunto de estímulos inicial e novos estímulos.

Greer, Stolfi e Pistoljevic (2007) compararam o procedimento de ICME com o treino de um único exemplar com crianças de 3 anos e 3 meses a 4 anos e 10 meses, com atraso no desenvolvimento da linguagem, e que não demonstravam o repertório de nomeação. As crianças que receberam ICME adquiriram nomeação. As crianças que receberam treino de exemplar único não atingiram o critério para aquisição de nomeação. Quando submetidas à ICME, essas crianças adquiriram nomeação. Nesse estudo, os autores apontaram que ainda não havia sido testada a emergência de nomeação com estímulos tridimensionais (objetos) e sugeriram que diferenças poderiam ser encontradas em estudos que utilizam estímulos bi e tridimensionais.

Com o objetivo de testar se um treino de tato seria suficiente para estabelecer o repertório de nomeação, Fiorile e Greer (2007) realizaram um estudo com quatro crianças diagnosticadas com autismo (2 a 2,4 anos) que não exibiam o repertório de nomeação nem tateavam estímulos bi ou tridimensionais. Após o treino de tato com estímulos tridimensionais, as crianças não apresentaram o repertório de nomeação. No entanto, quando expostas a um procedimento de ICME com estímulos tridimensionais, elas adquiriram nomeação e foram capazes de demonstrar respostas de ouvinte não ensinadas diretamente após um novo treino de tato com outros estímulos tridimensionais. Os autores sugerem que o aprendizado de nomeação com tipos particulares de estímulos, após o procedimento de ICME, não necessariamente implica ter nomeação com outros tipos de estímulos (estímulos bi ou tridimensionais, palavras impressas, etc.). 
Recentemente, Gilic e Greer (2011) verificaram que um procedimento de ICME com estímulos tridimensionais foi efetivo para estabelecer o repertório de nomeação em sete de oito crianças de 2 anos, sem atraso no desenvolvimento. No entanto, não foram encontrados, até o presente momento, estudos comparando diretamente a utilização de estímulos bidimensionais e tridimensionais em procedimentos de ICME para ensinar nomeação em pessoas com atraso no desenvolvimento e/ou linguagem.

O presente estudo comparou a utilização de estímulos bidimensionais e tridimensionais em um procedimento de ICME para ensinar nomeação a crianças diagnosticadas com autismo. Essa comparação permitiu avaliar: (a) a efetividade da ICME na instalação de nomeação nessa população; (b) se uma modalidade de estímulo é mais adequada para estabelecer nomeação; (c) se há diferenças na instalação de nomeação entre as modalidades de estímulos (como sugerem Fiorile \& Greer, 2007; Greer et al., 2007); e (d) se ocorre transferência de aprendizagem de nomeação entre as modalidades de estímulos.

\section{Método}

\section{Participantes}

Participaram do estudo quatro crianças diagnosticadas com transtorno do espectro autista, com atraso no desenvolvimento verbal, sem comorbidades e com baixa frequência de comportamentos auto e heterolesivos. Max (nomes fictícios) tinha 10 anos, nível de funcionamento verbal de 4 anos e 9 meses no Peabody Picture Vocabulary Test (PPVT; Dunn \& Dunn, 1997), diagnóstico realizado pela equipe do Projeto Caminhar do Hospital Universitário Bettina Ferro da Universidade Federal do Pará (UFPA), e recebia intervenção do tipo Applied Behavior Analysis (ABA três vezes por semana no projeto Atendimento e Pesquisa sobre Aprendizagem e Desenvolvimento (APRENDE; Barros, Souza, \& Assis, 2012). Fernando tinha 7 anos, nível de funcionamento verbal menor que 1 ano e 9 meses no PPVT, diagnóstico realizado pela equipe do Projeto Caminhar, e recebia intervenção do tipo $\mathrm{ABA}$ três vezes por semana no APRENDE. Dan tinha 5 anos, nível de funcionamento verbal de 5 anos e 11 meses no PPVT, diagnóstico realizado em consultório particular, e recebia intervenção do tipo ABA quatro vezes por semana em casa e em consultório particular. Pedro tinha 6 anos, nível de funcionamento verbal menor que 1 ano e 9 meses no PPVT, diagnóstico realizado pela equipe do Projeto Caminhar, e não recebia atendimento especializado na época.

Para a participação no estudo, foi necessária assinatura do termo de consentimento livre e esclarecido pelos responsáveis legais dos participantes. O presente trabalho foi aprovado pelo Comitê de Ética em Pesquisa do Instituto de Ciências da Saúde da UFPA, conforme o parecer n ${ }^{\circ} 175.303$ de 14/12/2012, em consonância com a Resolução 466/2012 do Conselho Nacional de Saúde (CNS/MS).

\section{Ambiente Experimental, Material e Equipamentos}

As sessões foram realizadas em uma sala $\left(36 \mathrm{~m}^{2}\right)$ de atendimento do APRENDE. A sala possui iluminação natural e artificial, é climatizada, possui um espelho unidirecional e está equipada com cadeiras e mesas para o uso com crianças pequenas. Para o registro, foram utilizados lápis, folhas de registro e uma câmera filmadora Sony 850 DCR.

\section{Estímulos}

Estímulos experimentais. Foram utilizados conjuntos de três formas geométricas não representacionais e suas fotos, bem como conjuntos de três diferentes tipos de bonecos e dinossauros em miniatura e suas fotos, com nomes arbitrariamente criados pelo experimentador e/ ou provenientes de outros estudos da área para um maior controle experimental (e.g., Dax, Zog, Tupa, etc) ${ }^{2}$. O número de conjunto de estímulos usados variou para cada participante em função de seu desempenho nas fases experimentais. As formas geométricas eram de cor azul e tinham aproximadamente $8 \mathrm{~cm} \times 12 \mathrm{~cm} \times 0,6 \mathrm{~cm}$ (3D) e $10 \mathrm{~cm}$ $x 15 \mathrm{~cm}$ (2D). Os brinquedos, por sua vez, eram de cores diversas e mediam aproximadamente $7 \mathrm{~cm} \times 2 \mathrm{~cm} \times 3 \mathrm{~cm}$ (3D) e $11 \mathrm{~cm} \mathrm{x} 9 \mathrm{~cm}(2 \mathrm{D})$.

Estímulos consequentes. Inicialmente, foi feito um levantamento de possíveis reforçadores com base na indicação dos cuidadores das crianças e das pessoas que trabalhavam com elas no APRENDE. Antes de cada sessão experimental, era realizado, uma única vez, um teste de preferência entre estímulos, com estímulos múltiplos sem reposição (Carr, Nicolson, \& Higbee, 2000), para escolher itens que pudessem funcionar como reforçadores, considerando a relação que existe entre preferência por estímulos e sua função reforçadora (DeLeon \& Iwata, 1996). Os estímulos do teste eram comestíveis (e.g., como chocolates, salgadinho e biscoitos) e brinquedos (e.g., como carros de brinquedo, tablet e bonecos). Ao ser dada a instrução $O$ que você quer? diante dos estímulos, o participante deveria dizer o nome, apontar ou pegar o item de sua escolha. Foi dada prioridade ao primeiro item escolhido, mas também poderiam ser utilizados o segundo e, no máximo, o terceiro. Ao fazer a seleção, o participante tinha acesso ao item por aproximadamente 30 segundos ou, no caso de comestíveis, o acesso durava até o consumo total do item. Além disso, consequências na forma de elogios e aprovação (e.g., como Muito bem!, Legal!), já utilizadas no atendimento diário dos participantes, foram empregadas concomitantemente aos itens provenientes da avaliação de preferência.

\section{Procedimento}

Foi utilizado um procedimento adaptado de ICME para ensino de nomeação, como proposto por Greer e

2 Uma figura com exemplos de estímulos experimentais e seus nomes pode ser encontrada em http://ppgtpc.propesp.ufpa.br/ARQUIVOS/ dissertacoes/Edson\%20santos\%202014.pdf 
colaboradores (e.g. Greer \& Longano, 2010; Greer \& Ross, 2008), constituído de quatro fases. A Fase 1 avaliou o desempenho de linha de base do repertório de nomeação em duas etapas: (a) treino de discriminações condicionais por identidade com tato dos estímulos modelo pelo experimentador (DCI+Tato); e (b) testes dos repertórios de discriminação condicional auditivo-visual (DCAV) e de tato. Prosseguiram no experimento os participantes que não passaram, em pelo menos uma das modalidades de estímulos, nos testes dos dois repertórios ou no de tato. A Fase 2 consistiu no treino dos repertórios de DCI+Tato, DCAV e tato com novos estímulos. Os participantes que atingiram o critério de aprendizagem na Fase 2 foram expostos novamente aos testes da Fase 1, com os mesmos estímulos usados naquela fase, para verificar a emergência de nomeação (Fase 3). Para os participantes que mostraram emergência de nomeação na Fase 3, foi replicada a Fase 1 com um novo conjunto de estímulos (Fase 4) para confirmar a aquisição do repertório.

Foi implementado um delineamento intrassujeito com um procedimento adaptado de alternância de tratamento. Desse modo, todos os participantes foram expostos às fases do experimento com estímulos bidimensionais e tridimensionais, diferindo apenas na ordem de apresentação de cada modalidade de estímulo, que foi balanceada entre os participantes para controlar possíveis efeitos de sequência do tipo de treino.

As sessões ocorreram, pelo menos, três vezes por semana. Eram realizadas no máximo duas sessões por dia (uma sessão com estímulos bidimensionais e outra com estímulos tridimensionais). Após uma sessão com uma modalidade de estímulo, havia um período de intervalo entre sessões de cinco minutos, no qual o participante podia se engajar em outras atividades. Em seguida, era realizada uma sessão com estímulos de modalidade diferente daquela da sessão anterior. Os estímulos de ambas as modalidades eram diferentes (não havia um mesmo estímulo em suas versões $3 \mathrm{D}$ e $2 \mathrm{D}$ sendo utilizados para um mesmo participante). $\mathrm{O}$ número de tentativas por sessão diferiu de acordo com a fase do experimento. $\mathrm{O}$ intervalo entre tentativas (IET) foi variável em função do tipo de reforçador utilizado.

Para manter o participante engajado na tarefa e evitar possíveis efeitos deletérios dos testes sem reforçamento, foi intercalado, entre as tentativas de testes, um procedimento remediativo que consistia em algumas tentativas reforçadas de tarefas que o participante já dominava, não relacionadas com o procedimento para ensino de nomeação (e.g., imitação motora, seguir instruções). Caso o participante não atingisse o critério de aprendizagem para algum conjunto de estímulos após seis sessões consecutivas de treino nas Fases 1 e 2, haveria a substituição do referido conjunto, até um máximo de duas substituições.

Fase 1 - Linha de base de nomeação. Essa fase começou com o treino de DCI+tato. Foram realizadas 18 tentativas randomizadas por sessão, seis para cada estímulo. Cada tentativa de DCI+Tato foi feita utilizando a instrução relacione <nome do estímulo $>$ enquanto o participante observava o estímulo modelo e as três comparações. Os estímulos comparação eram colocados sobre a mesa, em uma distância média entre o experimentador e o participante, e então era apresentado o estímulo modelo na mão do experimentador e dada a instrução. Respostas corretas (colocar o estímulo modelo sobre ou na direção do estímulo comparação idêntico dentro de um período de $5 \mathrm{~s}$ ) foram reforçadas. Se o participante emitisse uma resposta incorreta em $5 \mathrm{~s}$, o experimentador iniciava um procedimento de correção sem reforçamento e com ajuda física: a instrução era repetida, o estímulo modelo reapresentado e o experimentador dava ajuda física total, guiando a mão do participante com o estímulo modelo até o estímulo comparação correto. Não houve necessidade de esvanecimento da ajuda uma vez que, após poucas tentativas corrigidas com ajuda física total, os participantes respondiam de forma independente (sem dicas). $\mathrm{O}$ critério para encerramento do treino de DCI+Tato para cada modalidade foi de $88,88 \%$ de respostas independentes corretas em duas sessões consecutivas ou 100\% em uma única sessão.

Concluído o treino de DCI+Tato (que possibilitava um controle pelas propriedades visuais e/ou auditivas dos estímulos), o participante que apresentasse nomeação deveria ser capaz de responder como falante e ouvinte para os estímulos usados nesse treino. Essa capacidade foi avaliada nos testes, sem consequências diferenciais explícitas, de DCAV e tato. Cada repertório, para cada modalidade, foi avaliado em 18 tentativas randomizadas aleatoriamente (seis para cada estímulo), com um intervalo de 1 min entre cada tipo de teste.

Nas tentativas de teste de DCAV, o experimentador colocou todos os três estímulos do conjunto na mesa, de frente para o participante, e solicitou respostas de ouvinte diversas, como aponte <nome do estímulo $>$ e/ou qual o <nome do estímulo $>$ ? (os participantes já emitiam as respostas de apontar/selecionar alguns estímulos familiares). Foram consideradas respostas corretas apontar, pegar ou tocar no estímulo nomeado em até $5 \mathrm{~s}$. Apontar, pegar ou tocar mais de um estímulo de uma vez ou em sequência ou não responder dentro de $5 \mathrm{~s}$ contaram como erros.

Nas tentativas de teste de tato, o experimentador segurou o estímulo na frente do participante e perguntou $O$ que é isso?. Respostas corretas incluíam tatear o estímulo apresentado de forma exata (dizer apenas o nome do estímulo) ou expandida (dizer, por exemplo, Isso é X ou Isso se chama X) em até 5 $\mathrm{s}$ após a pergunta. Dizer parte do nome do estímulo, outro nome ou não responder em até $5 \mathrm{~s}$ contaram como erros.

Os testes foram realizados por repertório. Primeiro, foram feitos os testes de DCAV com ambas as modalidades de estímulos e depois os testes de tato. A ordem de apresentação de cada tipo de estímulo foi balanceada entre os participantes. O critério para passar nos testes de DCAV e tato foi de $88,88 \%$ de respostas independentes corretas, ou seja, 16 acertos nas 18 tentativas de teste.

Fase 2 - Instrução com múltiplos exemplares. Nessa fase, foram treinados os repertórios de DCI+Tato, DCAV e tato com novos conjuntos de três estímulos bidimensionais e tridimensionais. Cada sessão era composta por 36 tentativas, 12 para cada repertório treinado (quatro tentativas de cada repertório para cada estímulo). As tentativas de DCI+Tato foram como as do treino desse repertório na Fase 1. As tentativas de DCAV e de tato foram como as do teste desse repertório na Fase 1, mas respostas corretas eram 
reforçadas. A emissão de uma resposta incorreta ou omissão de resposta em $5 \mathrm{~s}$ levou a um procedimento de correção sem reforçamento com as seguintes características para cada repertório: DCAV - foram repetidas as perguntas aponte $<$ nome do estímulo $>$ e/ou qual $o<$ nome do estímulo $>$ ? e o experimentador guiou a mão do participante na direção do estímulo correto ou apontou para o estímulo correto; tato - foi repetida a pergunta $O$ que é isso?, em seguida, o estímulo foi nomeado, i.e, foi dada uma dica ecóica e o experimentador aguardava por uma resposta ecóica do participante em $5 \mathrm{~s}$. Não houve necessidade de esvanecimento das dicas uma vez que, após poucas tentativas corrigidas, os participantes respondiam de forma independente. No caso do tato, houve, no máximo, duas correções para cada tentativa incorreta. Se o participante não ecoasse em nenhuma dessas tentativas, o experimentador prosseguia para a tentativa seguinte. $\mathrm{O}$ critério para encerramento do treino com um conjunto de estímulos foi de $91,6 \%$ de respostas independentes corretas em duas sessões consecutivas para cada repertório ou $100 \%$ em uma única sessão.

Fase 3 - Teste de nomeação com o conjunto de estímulos da Fase 1. Aqueles participantes que atingissem o critério de aprendizagem dos repertórios treinados na Fase 2, com ambas ou apenas uma modalidade, poderiam ter sucesso em testes de nomeação com os estímulos utilizados na Fase 1, ou seja, poderiam passar nos testes de DCAV e tato. Supondo que o treino na Fase 2 tivesse estabelecido relações bidirecionais entre os repertórios de falante e ouvinte dos participantes, como eles haviam sido expostos apenas aos nomes dos estímulos no treino de DCI+tato, era possível que os participantes tivessem sucesso nos testes de respostas não ensinadas com tais estímulos, evidenciando aquisição de nomeação.

O teste foi uma replicação dos testes de DCAV e tato da Fase 1. Devido à complexidade da tarefa que envolvia treinos e testes com estímulos 2D e 3D (além da possibilidade de um treino extenso na Fase 2), foi realizada uma nova sessão de treino de DCI+tato para que o participante pudesse escutar novamente o nome dos estímulos na sua presença antes de ser testada a emergência de nomeação. Caso o participante não demonstrasse nomeação nos testes, sua participação no estudo era encerrada. Caso demonstrasse, era realizada a Fase 4.

Fase 4 - Treino de DCI+Tato e teste de nomeação com novos estímulos. Essa fase foi uma replicação completa da Fase 1 com novos estímulos para confirmar a aquisição do repertório e a confiabilidade dos dados. Desempenhos consistentes nos testes de DCAV e tato confirmariam a emergência de nomeação. Desempenhos inconsistentes nos testes de DCAV e tato demonstrariam que a nomeação não emergiu plenamente e que o desempenho na Fase 3 pode ter sido favorecido pela exposição prévia aos estímulos.

Durante as sessões experimentais, um experimentador registrou as respostas dos participantes para cada tentativa de cada repertório treinado ou testado em uma folha de registro específica. Todas as sessões do experimento foram filmadas. Um segundo experimentador, que estava ciente do objetivo do estudo, fez o registro de $30 \%$ das sessões de cada participante, para estabelecer um índice de concordância entre observadores [(Concordância/Concordâncias +
Discordância) x 100] do registro dos repertórios treinado ou testado. Foram utilizados como critérios para avaliar a concordância, a topografia da resposta (correspondência ponto a ponto com a forma verbal padrão no caso do tato, repostas de seleção - pegar ou tocar o estímulo nomeado - no caso de DCAV e colocar o estímulo modelo sobre ou na direção do estímulo comparação idêntico no caso de DCI+tato) e a sua ocorrência em até $5 \mathrm{~s}$ após a solicitação da mesma pelo experimentador. Obteve-se uma concordância entre observadores que variou de $92,77 \%$ a $99,6 \%$.

\section{Resultados}

Todos os participantes alcançaram o critério de aprendizagem nos treinos de DCI+tato em uma ou duas sessões em todas as fases do experimento. As Figuras 1 (participantes Max e Fernando) e 2 (participantes Dan e Pedro) mostram os percentuais de respostas corretas nos testes e treinos de DCAV e tato.

Nos painéis à esquerda da Figura 1, encontram-se os resultados de Max com as formas geométricas não representacionais 2D (painel superior) e 3D (painel intermediário). Na Fase 1, Max obteve, para os estímulos 2D, $38,88 \%$ de acertos no teste de DCAV e $22,22 \%$ de acertos no teste de tato. Já com os estímulos $3 \mathrm{D}$, o participante atingiu $38,88 \%$ de acertos no teste de DCAV e não houve acerto no teste de tato. Na Fase 2, foram necessárias três sessões com estímulos 2D e quatro com estímulos 3D para que Max atingisse o critério de aprendizagem. O participante finalizou o treino da Fase 2 com $100 \%$ de acertos em tato e DCAV com os estímulos 2D, bem como $100 \%$ em DCAV e $91,66 \%$ nas duas últimas sessões de tato com os estímulos 3D.

Na Fase 3, os testes de DCAV e tato com os estímulos usados na Fase 1 foram replicados para avaliar se o treino da Fase 2 havia sido suficiente para produzir nomeação. Nos testes com os estímulos 2D, Max atingiu 100\% de acertos em ambos os repertórios (evidência da emergência de nomeação) e, assim, foi realizada a Fase 4 com essa modalidade de estímulos. Por outro lado, com os estímulos 3D Max alcançou $27,77 \%$ de acertos nos testes de ambos os repertórios, o que mostrou que a nomeação não havia emergido para aquela modalidade de estímulo. Desse modo, foi encerrada a coleta de dados com os estímulos 3D. Na Fase 4, após uma sessão de DCI+tato com estímulos 2D novos, Max apresentou 66,66\% de acertos no teste de DCAV e 55,55\% no teste de tato.

Os resultados da Fase 4 não confirmaram a aquisição de nomeação. Considerou-se a possibilidade de que estímulos antropomórficos pudessem ser facilitadores do aprendizado em relação aos estímulos não antropomórficos (Lodhi \& Greer, 1989). Em função disso, o procedimento foi replicado com Max, utilizando estímulos convencionais, como brinquedos, não usuais para o participante (bonecos e dinossauros em miniatura, e suas fotos, designados com nomes arbitrários). Durante a Fase 1 com os brinquedos, Max obteve $100 \%$ de acertos nos testes de DCAV e tato com os estímulos 2D (dado não apresentado), o que significou demonstração de nomeação e encerramento da coleta com essa modalidade de estímulos. Já com os estímulos 3D (Painel inferior), os percentuais de acertos foram de 77,77\% 


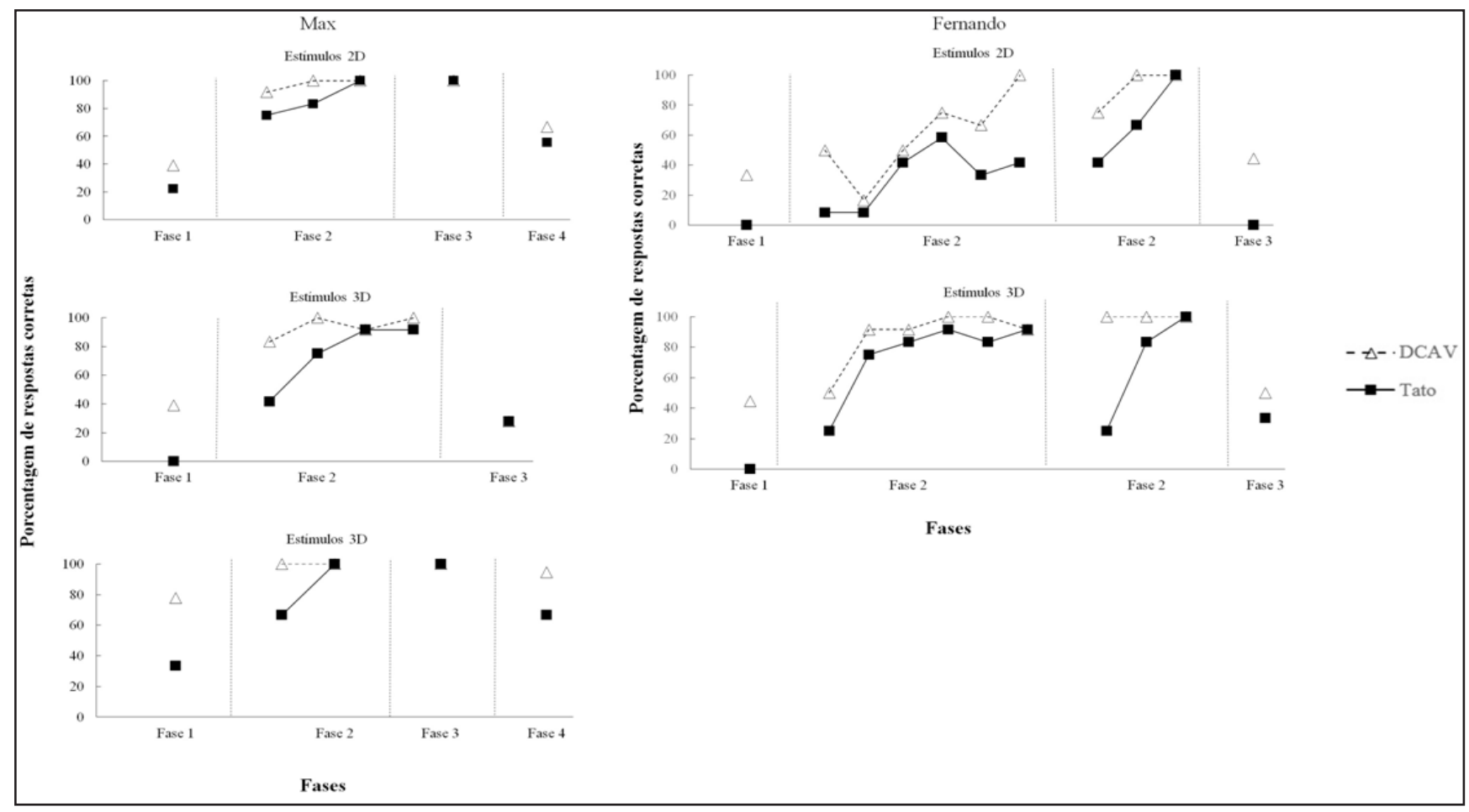

Figura 1: Percentual de respostas corretas nos testes e treinos de DCAV e tato para Max (esquerda) e Fernando (direita). Para Max, o gráfico corresponde aos dados com formas geométricas 2D (painel superior) e 3D (painel intermediário) e estímulos convencionais como estímulos 3D (painel inferior). Para Fernando, a Fase 1 e a primeira Fase 2 foram realizadas com formas geométricas como estímulos 2D (painel superior) e 3D (painel inferior). A segunda Fase 2 e a Fase 3 foram realizadas com estímulos convencionais. Na Fase 2, cada ponto no gráfico corresponde a uma sessão de treino

em DCAV e 33,33\% em tato. Na Fase 2, Max alcançou o critério de aprendizagem em apenas duas sessões, finalizando o treino com $100 \%$ de acertos em tato e DCAV. Nos testes da Fase 3, Max demonstrou aquisição de nomeação com 100\% de acertos em ambos os repertórios. No entanto, na Fase 4, após uma sessão de DCI+tato com estímulos $3 \mathrm{D}$ novos, o participante confirmou apenas a aquisição do componente de ouvinte da nomeação, com $94,44 \%$ de acertos no teste de DCAV, mas não o componente de falante, com $66,66 \%$ de acertos no teste de tato.

A Figura 1 também apresenta os percentuais de respostas corretas de Fernando nos testes e treinos de DCAV e tato com estímulos 2D e 3D (Painel superior e inferior, respectivamente). Na Fase 1, com as formas geométricas como estímulos 2D, Fernando obteve $33,33 \%$ de acertos no teste de DCAV e nenhum acerto no teste de tato. Já com as formas geométricas como estímulos 3D, Fernando acertou $44 \%$ das tentativas de DCAV e nenhuma tentativa de tato. Na Fase 2, Fernando passou inicialmente por seis sessões de treino com cada modalidade de estímulo sem alcançar o critério de aprendizagem. Esse primeiro treino foi encerrado com $100 \%$ de acertos em DCAV e $41,66 \%$ em tato com os estímulos 2D, e 91,66\% de acertos em ambos os repertórios com os estímulos 3D. De acordo com o planejamento experimental, foi realizada a substituição de estímulos para ambas as modalidades. No entanto, as formas geométricas foram substituídas por brinquedos. Com os novos conjuntos, Fernando alcançou o critério de aprendizagem em três sessões em ambas as modalidades de estímulos, atingindo, ao final da replicação da Fase 2, 100\% de acertos nos dois repertórios em ambas as modalidades. Como as formas geométricas foram substituídas na Fase 2 pelos brinquedos, na Fase 3 (replicação da Fase 1), foi realizado o treino de DCI+tato com um novo conjunto de brinquedos e, subsequentemente, os testes de DCAV e tato com esses novos estímulos. Nos testes, Fernando não demonstrou aquisição de nomeação, obtendo 44,44\% de acertos em DCAV e nenhum acerto em tato com os estímulos $2 \mathrm{D}$, bem como $50 \%$ de acertos em DCAV e 33,33\% em tato com os estímulos 3D.

A Figura 2 apresenta os resultados de Dan (esquerda) e Pedro (direita). Para esses participantes, a coleta de dados foi realizada utilizando estímulos convencionais em todas as fases experimentais. Na Fase 1, Dan alcançou, para os estímulos 2D (painel superior), $88,88 \%$ de acertos no teste de DCAV e $55,55 \%$ no teste de tato. Com os estímulos 3D (painel inferior), seu desempenho foi de $100 \%$ de acertos no teste de DCAV e 66,66\% em tato. Na Fase 2, Dan necessitou de três sessões com os estímulos $2 \mathrm{D}$ e seis sessões com os estímulos 3D para alcançar o critério para encerramento do treino. Ele finalizou a Fase 2 com $100 \%$ e 91,66\% de acertos nas duas últimas sessões de treino de DCAV, respectivamente, e $100 \%$ de acertos na última sessão de tato com os estímulos 2D. Já com os estímulos 3D, houve 100\% de acertos na última sessão de DCAV e 91,66\% de acertos nas duas últimas sessões de tato.

Na Fase 3 (replicação dos testes da Fase 1), Dan demonstrou nomeação com ambas as modalidades de estímulos. Ele obteve $100 \%$ de acertos em DCAV e $88,88 \%$ de acertos em tato com estímulos 2D, e $100 \%$ de acertos em DCAV e $94,44 \%$ de acertos em tato com estímulos 3D. 


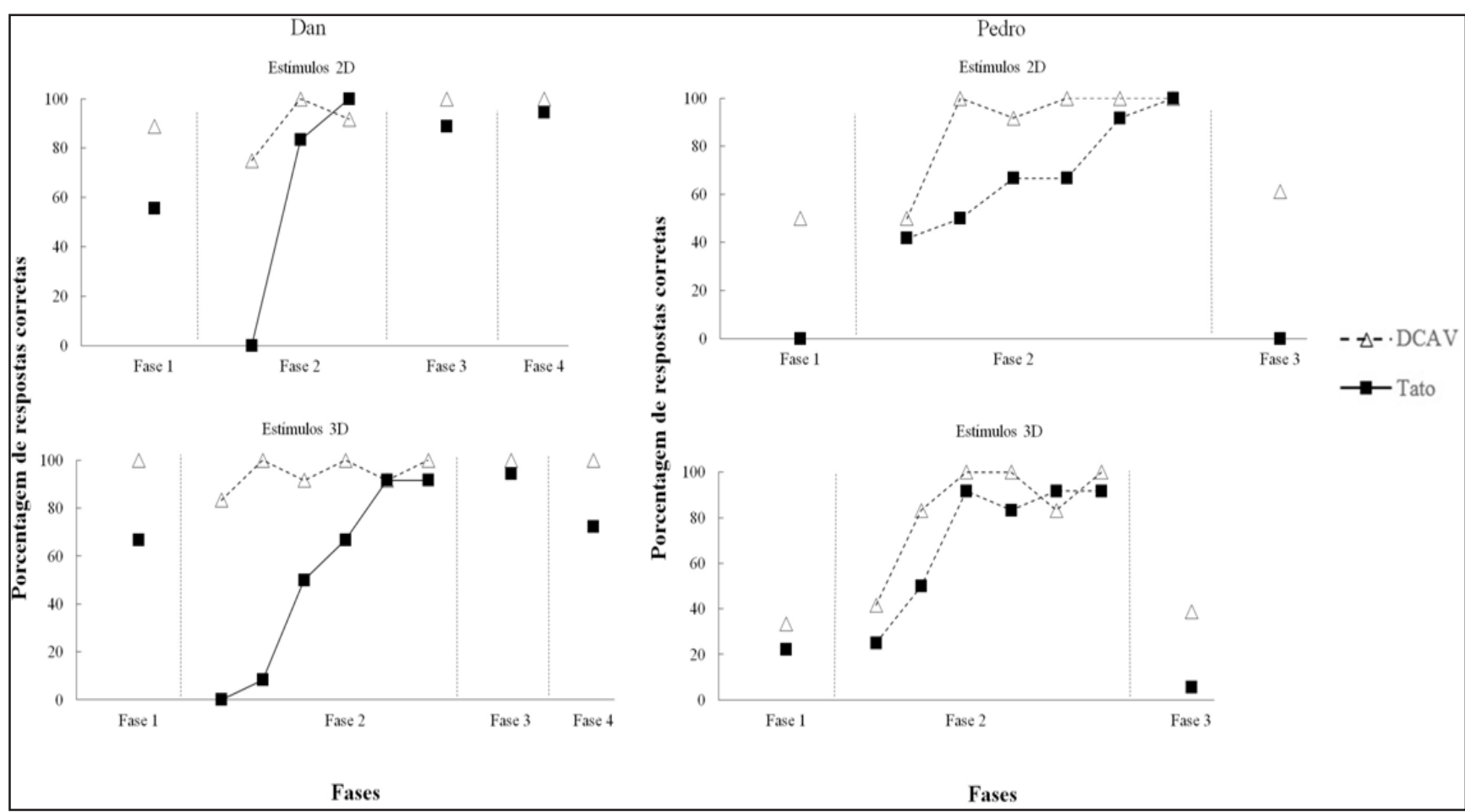

Figura 2. Percentual de respostas corretas nos testes e treinos de DCAV e tato para Dan (esquerda) e Pedro (direita). Para estes participantes, os gráficos correspondem aos dados com estímulos convencionais 2D (painel superior) e 3D (painel inferior). Na Fase 2, cada ponto no gráfico corresponde a uma sessão de treino

Na Fase 4, após duas sessões de DCI+tato com estímulos 2D e 3D novos, Dan obteve $100 \%$ de acertos em DCAV e $94,44 \%$ de acertos em tato com os estímulos 2D, confirmando aquisição de nomeação com essa modalidade de estímulos. Com os estímulos 3D, o participante apresentou $100 \%$ de acertos em DCAV e 72,22\% em tato, mostrando a aquisição apenas do componente de ouvinte da nomeação.

O percentual de respostas corretas de Pedro nos testes e treinos de DCAV e tato com estímulos 2D (Painel superior) e 3D (Painel inferior) também podem ser consultados na Figura 2. Na Fase 1, Pedro atingiu 50\% de acertos no teste de DCAV e nenhum acerto no teste de tato com os estímulos 2D. Já na modalidade 3D, o desempenho de Pedro foi de $33,33 \%$ de acertos em DCAV e $22,22 \%$ no tato. Na Fase 2 , Pedro atingiu o critério de aprendizagem em seis sessões com ambas as modalidades de estímulos. O participante finalizou o treino com $100 \%$ de acertos em DCAV e tato com os estímulos 2D, bem como $100 \%$ em DCAV e $91,66 \%$ nas duas últimas sessões de tato com os estímulos 3D. Na Fase 3, Pedro obteve $61,11 \%$ de acertos em DCAV e nenhum acerto em tato com os estímulos 2D. Com os estímulos 3D, o participante alcançou 38,88\% de acertos em DCAV e 5,55\% em tato. Como não houve emergência de nomeação, a coleta de dados com Pedro foi encerrada.

Em síntese, verificou-se a emergência de nomeação com dois participantes: Max e Dan. Max apresentou nomeação com formas geométricas como estímulos 2D e com brinquedos como estímulos 3D nos testes de Fase 3, mas esse desempenho não se confirmou nos testes de Fase 4. Esse participante apresentou apenas o componente de ouvinte da nomeação com brinquedos como estímulos 3D na Fase 4. Ele demonstrou nomeação com fotos de brinquedos como estímulos 2D nos testes da Fase 1, após o procedimento de ICME com formas geométricas como estímulos 2D e 3D. Dan apresentou nomeação com fotos de brinquedos como estímulos $2 \mathrm{D}$ e com brinquedos como estímulos $3 \mathrm{D}$ nos testes de Fase 3, mas esse repertório se confirmou apenas com os estímulos 2D dos testes na Fase 4. Com os estímulos 3D, Dan apresentou apenas o componente de ouvinte da nomeação na Fase 4. O procedimento de ICME não foi suficiente para ensinar nomeação para Fernando e Pedro.

\section{Discussão}

Este estudo comparou a utilização de estímulos bidimensionais e tridimensionais em um procedimento de ICME para produção de nomeação em crianças diagnosticadas com autismo. Os resultados de Max e Dan sugerem uma maior facilidade em produzir nomeação com estímulos bidimensionais. No caso de Max, embora a diferença no número de sessões de ICME para atingir o critério de aprendizagem com as formas geométricas como estímulos 2D e 3D tenha sido mínima, apenas houve demonstração de nomeação na Fase 3 com os estímulos 2D. Além disso, na replicação do procedimento com brinquedos como estímulos, Max demonstrou nomeação com os estímulos 2D já na Fase 1, precisando de duas sessões de ICME para alcançar o critério de aprendizagem com os estímulos 3D. Esses resultados sugerem ainda uma maior facilidade de aprendizado de nomeação com estímulos naturais/convencionais (e.g., brinquedos) em comparação com estímulos não convencionais (e.g., formas geométricas não representacionais) que precisa ser melhor investigada. 
O melhor desempenho com estímulos 2D ficou mais evidente nos resultados de Dan. Esse participante precisou de três sessões de ICME na Fase 2 com estímulos 2D para atingir o critério de aprendizagem. Por outro lado, foram necessárias seis sessões de treino com estímulos 3D. Apesar de se verificar a emergência de nomeação na Fase 3 com ambas as modalidades de estímulos, Dan confirmou, na Fase 4, a emergência da relação completa de nomeação (repertórios de ouvinte e falante) apenas com os estímulos 2D. Com estímulos 3D, assim como Max, ele atingiu o critério apenas para o componente de ouvinte da nomeação.

Os resultados de Max e Dan estão de acordo com estudos da área que demonstram a efetividade do procedimento de ICME para produzir nomeação em crianças com ou sem atraso no desenvolvimento (Fiorile \& Greer, 2007; Gilic \& Greer, 2011; Greer et al., 2005; Greer et al., 2007). Na Fase 4 com brinquedos como estímulos 3D, Max e Dan mostraram a emergência apenas do componente de ouvinte da nomeação, reforçando as sugestões de que os componentes de nomeação podem emergir separadamente (Greer et al., 2005; Greer et al., 2007; Horne et al., 2004; Lowe et al., 2005) e, consequentemente, da independência, durante a aquisição, das funções verbais de falante e ouvinte (Petursdottir \& Carr, 2011; Skinner, 1957/1992). Por outro lado, nas etapas de treino com os participantes, o percentual de respostas de ouvinte, em geral, foi superior ao de respostas de falante, o que sugere que, apesar da independência entre os repertórios, o aprendizado das respostas de ouvinte pode favorecer o aprendizado de respostas de falante.

A não confirmação da aquisição completa de nomeação na Fase 4 com Max e, por outro lado, a confirmação desse repertório na Fase 4 (com estímulos 2D) com Dan podem ser indicativos de que a quantidade de exposição aos nomes dos estímulos na sua presença exerce um papel importante na emergência da relação de nomeação com novos estímulos. No presente estudo, essa exposição foi realizada com o treino de DCI+tato. Na Fase 4 com Dan, foram realizadas duas sessões de treino de DCI+tato, contra apenas uma sessão de treino com Max. Considerando que apenas Max e Dan atingiram a Fase 4 no estudo, esses resultados necessitam ser replicados para reforçar essa hipótese. Além disso, podem ser exploradas variações paramétricas na quantidade de exposição aos nomes de estímulos.

Com Fernando e Pedro, não houve emergência da relação de nomeação após nove e seis sessões, respectivamente, de ICME. O desempenho de Fernando pode ter sido influenciado por sua dificuldade em produzir alguns sons da fala. Embora fosse submetido a tratamento fonoaudiológico, os seus repertórios de ecoar e tatear apresentavam certo comprometimento. Sabe-se da importância do comportamento ecóico no aprendizado de tato e nomeação (Greer \& Ross, 2008; Horne \& Lowe, 1996; Skinner, 1957/1992). O desempenho de tato de Fernando evoluiu até o critério de aprendizagem com a implementação dos procedimentos corretivos e do reforçamento direto das respostas. Estudos futuros sobre emergência de nomeação com crianças com as mesmas dificuldades de Fernando, ou aquelas que não obtenham sucesso após tentativas de ensino, podem se beneficiar de procedimentos que fortaleçam a correspondência ponto-a-ponto do repertório de ecóico previamente ao treino de tato e/ou explorem procedimentos alternativos para a emergência de nomeação (Greer \& Longano, 2010; Greer \& Ross, 2008).

É possível que Pedro adquirisse nomeação caso fossem repetidos os treinos da Fase 2 com novos estímulos. Atendendo a critérios experimentais, essa repetição de treino não foi realizada. No entanto, estudos indicam que crianças que não aprendem nomeação após uma única etapa de ICME podem fazê-lo caso essa etapa seja realizada novamente com outros estímulos (Fiorile \& Greer, 2007; Greer et al., 2007). Novos estudos podem relacionar a quantidade de exposição ao treino necessária para produzir nomeação e o repertório de linha de base dos indivíduos.

Embora alguns estudos demonstrem a efetividade da ICME na aquisição de nomeação (Fiorile \& Greer, 2007; Greer et al., 2005; Greer et al., 2007; Gilic \& Greer, 2011), apenas dois dos quatro participantes do presente estudo adquiriram nomeação após serem expostos ao referido treino. Isso sugere uma efetividade limitada, ao menos para os participantes deste estudo. Talvez, se os participantes que não apresentaram nomeação fossem expostos a procedimentos mais similares ao que ocorre em ambiente natural, como procedimentos que envolvam apenas o pareamento entre um objeto e seu nome (Longano, 2008; Stemmer, 1996) ou ao ensino de tatos de modo intensivo (Greer \& Longano, 2010; Greer \& Ross, 2008), eles tivessem adquirido nomeação.

Um fator que pode ter afetado o desempenho nos testes de nomeação, de forma geral, foi o elevado número de tentativas sem reforçamento dos repertórios testados, com reforços apenas nas tentativas de outros repertórios já adquiridos (ver procedimento). Embora as tentativas reforçadas pudessem remediar prováveis efeitos da ausência de reforço nas tentativas de teste, tais efeitos podem ter interferido nos resultados em razão da sua alta densidade (18 tentativas de cada repertório por modalidade de estímulo). Em estudos futuros, ou em situações aplicadas, para evitar possíveis efeitos deletérios da ausência de reforço, pode ser adequado fracionar os testes em blocos de poucas tentativas (duas ou três), intercaladas com pelo menos o dobro de tentativas de manutenção, ou procurar realizar testes sem reforço das primeiras tentativas de cada estímulo nos diferentes tipos de testes.

Não foram observados efeitos de transferência de aprendizagem de nomeação entre modalidades de estímulos, confirmando a sugestão de Fiorile e Greer (2007) e Greer et al. (2007) de que a aquisição de nomeação com tipos particulares de estímulos não implica necessariamente emergência de nomeação com outros tipos de estímulos. Talvez uma adaptação do procedimento, que alterne treinos de diferentes modalidades/tipos dos mesmos estímulos (e.g., uma bola, sua foto, a palavra bola escrita, etc.) facilite a transferência, assim como o treino alternado entre respostas de falante e ouvinte produz integração desses repertórios. Uma melhor compreensão sobre os efeitos de transferência de aprendizagem de nomeação é importante porque a literatura sugere que uma vez que esse repertório tenha sido adquirido, novos repertórios podem ser aprendidos, tais como categorização e leitura, pela mediação que o nome em comum entre diferentes tipos de estímulos pode estabelecer 
(Greer \& Longano, 2010; Greer \& Speckman, 2009; Horne \& Lowe, 1996).

Diferentemente de Gilic e Greer (2011), que instalaram nomeação com estímulos $3 \mathrm{D}$, o presente estudo possibilitou uma comparação direta da aquisição de nomeação com estímulos 2D e 3D em crianças diagnosticadas com autismo. Essa comparação pode ser relevante para a área aplicada porque sugere que uma modalidade de estímulo (2D) pode ser mais apropriada para induzir nomeação, por exemplo, em indivíduos que não aprendem esse repertório nas situações do cotidiano e necessitam de instrução direta.

A nomeação é um repertório ao qual se aplica o conceito de cúspide comportamental (behavioral cusp; RosalesRuiz \& Baer, 1997). Uma cúspide comportamental é qualquer mudança de comportamento que permite que o indivíduo possa entrar em contato com novas situações de aprendizagem (contingências) que ele não podia contatar previamente à mudança. Após a aquisição de uma cúspide, uma série de desenvolvimentos subsequentes se torna facilitada ou mais provável. Assim, ao aprender a andar, por exemplo, uma criança expande seu acesso ao ambiente e entra em contato direto com novas contingências que antes não poderia acessar.

Algumas cúspides são também capacidades do desenvolvimento (Greer \& Longano, 2010; Greer \& Ross, 2008; Greer \& Speckman, 2009). Ao adquirir uma capacidade, indivíduos não apenas passam a entrar em contato com novas situações de aprendizagem, mas também são capazes de aprender de modos que não podiam antes. Nomeação é uma capacidade do desenvolvimento verbal na medida em que permite que indivíduos aprendam incidentalmente, sem instrução direta. Esse aprendizado incidental acelera exponencialmente o desenvolvimento dos indivíduos, o que reitera a importância para a área aplicada de dados sobre variáveis relevantes na instalação de nomeação.

Uma limitação do presente estudo foi que o repertório verbal de entrada dos participantes foi avaliado apenas com a aplicação do PPVT (Dunn \& Dunn, 1997) e pela linha de base na Fase 1. Não foram feitos outros registros do desempenho verbal dos participantes, principalmente no que concerne aos repertórios de tato de estímulos cotidianos e de ecóico. Informações sobre esses repertórios poderiam ter ajudado a adaptar o procedimento de treino para Fernando e Pedro de modo a garantir certos repertórios pré-requisitos antes da ICME.

Por outro lado, os participantes que não apresentaram nomeação foram aqueles que tiverem os mais baixos escores no PPVT. Isso indica possíveis déficits no repertório de ouvinte que podem ter dificultado a aquisição de nomeação. Greer e Keohane (2005) discutem a importância do repertório de ouvinte para o avanço do desenvolvimento verbal. Afirmam que podem ser encontradas dificuldades na aquisição de repertórios comportamentais complexos na ausência de repertórios de ouvinte, o que foi confirmado pelos resultados dos participantes Max e Dan, que tiveram os maiores escores no PPVT e, em alguma parte do estudo, demonstraram aprendizado de nomeação. Os componentes do repertório de ouvinte dos participantes do presente estudo não foram avaliados detalhadamente. Sugere-se que estudos futuros avaliem mais cuidadosamente os repertórios de ouvinte e seus subcomponentes pré-requisitos.

De forma geral, os dados do presente estudo confirmam a efetividade do procedimento de ICME na instalação de nomeação em crianças diagnosticadas com autismo e sugerem que o uso de estímulos $2 \mathrm{D}$ pode facilitar a emergência desse repertório. Novos estudos devem buscar replicar esses resultados e expandir a investigação para outras modalidades sensoriais (tátil, olfativa), o que seria relevante para a compreensão do aprendizado de nomeação e poderia ampliar o conhecimento sobre a integração sensorial em pessoas com autismo. A transferência entre modalidades também necessita ser investigada. Isso pode ser feito a partir de procedimentos que treinem nomeação apenas com uma modalidade e testem a emergência com outras.

\section{Referências}

Barros, R. S., Souza, C. B. A., \& Assis, G. J. A. (2012). APRENDE: Atendimento e Pesquisa sobre Aprendizagem e Desenvolvimento (Projeto de Pesquisa). Programa de Pós-graduação em Teoria e Pesquisa do Comportamento, Universidade Federal do Pará, Belém.

Carr, J. E., Nicholson, A. C., \& Higbee, T. S. (2000). Evaluation of a brief multiple-stimulus preference assessment in a naturalistic context. Journal of Applied Behavior Analysis, 33, 353-357. doi: 10.1901/jaba.2000.33-353

DeLeon, I. G., \& Iwata, B. A. (1996). Evaluation of a multiplestimulus presentation format for assessing reinforcer preferences. Journal of Applied Behavior Analysis, 29, 519532. doi: 10.1901/jaba.1996.29-519

Dunn, L. M., \& Dunn, L. M. (1997). Peabory Picture Vocabulary Test. Circle Pines. MN: American GuiDance Service

Fiorile, C. A., \& Greer, R.D. (2007). The induction of naming in children with no prior tact responses as a function of multiple exemplar histories of instruction. The Analysis of Verbal Behavior, 23, 71-87.

Gilic, L., \& Greer, R. D. (2011). Establishing naming in typically developing two-year-old children as a function of multiple exemplar speaker and listener experiences. The Analysis of Verbal Behavior, 27, 157-177.

Greer, R. D., \& Keohane, D. D. (2005). The evolution of verbal behavior in children. Behavioral Development Bulletin, 1, 31-47.

Greer, R. D., \& Longano, J. (2010). A rose by naming: How we may learn how to do it. The Analysis of Verbal Behavior, 26, 73-06.

Greer, R. D., \& Ross, D. E. (2008). Verbal Behavior Analysis: Inducing and expanding new verbal capabilities in children with language delays. Boston: Pearson Education.

Greer, R. D., \& Speckman, J. (2009). The integration of speaker and listener responses: A theory of verbal development. The Psychological Record, 54, 449-488.

Greer, R. D., Stolfi, L., Chavez-Brown, M., \& Rivera-Valdes, C. (2005). The emergence of the listener to speaker component of naming in children as a function of multiple exemplar instruction. The Analysis of Verbal Behavior, 21, 123-134. 
Greer, R. D., Stolfi, L., \& Pistoljevic, N. (2007). Emergence of Naming in preschoolers: A comparison of multiple and single exemplar instruction. European Journal of Behavior Analysis, 8, 119-131.

Horne, P. J., Hughes, J. C., \& Lowe, C. F. (2006). Naming and categorization in young children: IV: Listener behavior training and transfer of function. Journal of the Experimental Analysis of Behavior, 85, 247-273. doi: 10.1901/jeab.2006.125-04

Horne, P. J., \& Lowe, C. F. (1996). On the origins of naming and other symbolic behavior. Journal of the Experimental Analysis of Behavior, 65, 185-241. doi: 10.1901/jeab.1996.65-185

Horne, P. J., Lowe, C. F., \& Harris, F. D. A. (2007). Naming and categorization in young children: V. Manual sign training. Journal of the Experimental Analysis of Behavior, 87, 367-381. doi: 10.1901/jeab.2007.52-06

Horne, P. J., Lowe, C. F., \& Randle, V. R. L. (2004). Naming and categorization in young children: II. Listener behavior training. Journal of the Experimental Analysis of Behavior, 81, 267-288. doi: 10.1901/jeab.2004.81-267

Lodhi, S., \& Greer, R. D. (1989). The speaker as listener. Journal of the Experimental Analysis of Behavior, 51, 353-359. doi: 10.1901/jeab.1989.51-353

Longano, J. M. (2008). The effects of echoic behavior and a second order classical conditioning procedure as a history of reinforcement for emergent naming (Tese de doutorado não publicada). Columbia University, New York.
Lowe, C. F., Horne, P. J., Harris, F. D. A., \& Randle, V. R. L. (2002). Naming and categorization in young children: Vocal tact training. Journal of the Experimental Analysis of Behavior, 78, 527-549. doi: 10.1901/jeab.2002.78-527

Lowe, C. F., Horne, P. J., \& Hughes, J. C. (2005). Naming and categorization in young children III: Vocal tact training and transfer of function. Journal of Experimental Analysis of Behavior, 83, 47-65. doi: 10.1901/jeab.2005.31-04

Petursdottir, A. I., \& Carr, J. E. (2011) A review of recommendations for sequencing receptive and expressive language instruction. Journal of Applied Behavior Analysis, 44, 859-876. doi: 10.1901/jaba.2011.44-859

Rosales-Ruiz, J., \& Baer, D. M. (1997). Behavioral cusps: A developmental and pragmatic concept for behavior analysis. Journal of Applied Behavior Analysis, 30, 533-544. doi: 10.1901/jaba.1997.30-533

Skinner, B. F. (1992). Verbal behavior. Acton, MA: Copley Publishing Group and The B. F. Skinner Foundation. (Trabalho original publicado em 1957)

Stemmer, N. (1996). Listener behavior and ostensive learning. Journal of the Experimental Analysis of Behavior, 65, 247-249. doi: 10.1901/jeab.1996.65-247

Recebido em 09.07.2014

Primeira decisão editorial em 27.02.2015

Versão final em 01.06.2015

Aceito em 01.06.2015 